\title{
Psychiatry of old age
}

\section{Senior registrars in the psychiatry of old age: a new group within the College}

Gianetta Rands, Inaugural Chairman of the Senior Registrars in the Psychiatry of Old Age Group, The Royal College of Psychiatrists

The Senior Registrars (SRs) in the Psychiatry of Old Age (POA) group was formed in June 1990. This is an account of our creation, structure, and development and is followed by our 'policy statement'.

\section{History}

In March 1990 the section of POA received a report from the SRs of the British Geriatric Society (BGS) summarising their findings of a questionnaire survey concerning details of their higher training. (See publication by Forsyth, February 1992, Psychiatric Bulletin, 16, 78-79.) It was evident that we did not have an equivalent group to respond to this approach, or a mechanism for identifying SRs interested in POA and hence organising a similar questionnaire. In April 1990, at the SRs' meeting at Warwick, an informal group of SRs interested in POA decided to organise such a group.

A circular was sent to all members of the section informing them of our first meeting and requesting the names of interested SRs. This trawl yielded 54 names and our first meeting was attended by 28 members.

\section{Structure}

At our first meeting a working party was elected to organise a response to the BGS survey and a member of that working party was selected to attend the BGS/POA Liaison Committee.

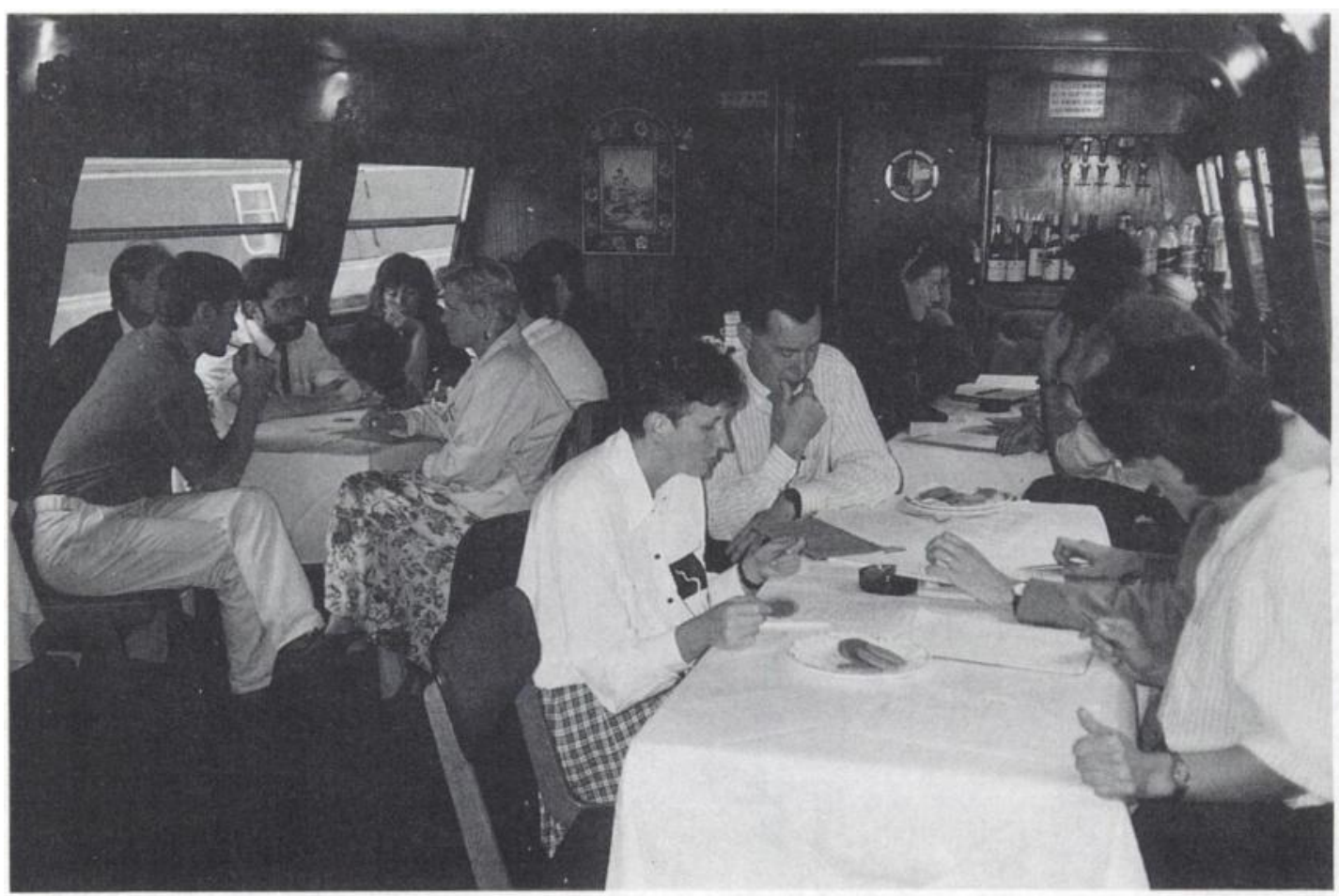

Working on our Policy Statement while cruising along Regent's Canal, September 1991. 
It was agreed that we would have a chairman (Dr G. Rands), secretary (Dr I. Leonard), and fund co-ordinator (Dr C. Kelly) elected by postal ballot, and that we would organise our list of members into regions, each with a regional representative. The Collegiate Training Committee (CTC) representative (then Dr S. McGauran, now Dr O. Junaid) was also welcomed as a member of our group.

\section{Review of our first year}

Quarterly formal meetings have occurred and been lively and well attended. Our minutes are now circulated, along with those of the section's business and executive committee meetings, to all members of the section.

Two further items of research were fostered by discussions within this group. They were a survey of study leave availability, funding, and regional policies nationwide, and an analysis of job descriptions for consultant appointments in POA.

Throughout the past year members of the section have been consistently supportive and encouraging towards the SRs' group. The need for such a group is evidenced by our success, and other sections may like to consider whether an equivalent group would be appropriate for them. With the rapid turnover of members and changes in services and training, the structure of such a group should be sufficiently flexible to accommodate emergent needs. Functions that are likely to persist are the group's role as a higher training resource for its members and the companionship inherent in a network such as this.

\section{The Policy Statement of Senior Registrars in the Psychiatry of Old Age}

The aims of this group are:

1. to represent senior trainees in the Psychiatry of Old Age
2. to exist as a subgroup of the section of Psychiatry of Old Age, within the Royal College of Psychiatrists

3. to accommodate our shifting membership within a nationwide network, with central representation

4. to share information and concerns about aspects of our training

5. to facilitate exchange of information between our members and represent our interests at relevant meetings and committees

6. to develop a political awareness on issues relevant to the Psychiatry of Old Age

7. to facilitate and support research by our members

8. to create an awareness of job opportunities in Psychiatry of Old Age

9. to foster lasting professional relationships.

\section{Our main activities are:}

1. to meet formally, keeping minutes, and socially at section meetings, and to arrange extraordinary and/or educational meetings as necessary

2. to have an annual election of officers to form an executive

3. to have a system of elected regional representatives to liaise with members

4. to elect working parties as necessary to respond to particular issues

5. to publish findings that may be of general interest or of assistance to other people in higher training

6. to have representatives attend other meetings such as the Executive Committee meeting and the POA/BGS Liaison Committee, and to welcome information from our members who are also elected representatives of the Collegiate Training Committee

7. to make public responses, after central meetings or networking, to political or public issues concerning our group as professionals. 